\title{
ESTABLISHING FREEZE DRYING PROCESS FOR CORTICAL AND CANCELLOUS BONE ALLOGRAFT CUBES
}

\author{
Ariffin AA, Chan HH, Yusof N, Mohd S, Ramalingam S, Ng WM, Mansor A. \\ Bone Bank \\ National Orthopaedic Centre of Excellence in Research and Learning (NOCERAL) \\ Department of Orthopaedic Surgery, Faculty of Medicine, University of Malaya \\ 50603 Kuala Lumpur, Malaysia
}

\section{Correspondence:}

Ms Suhaili Mohd

National Orthopaedic Centre of Excellence in Research and Learning (NOCERAL)

Department of Orthopaedic Surgery, Faculty of Medicine, University of Malaya

50603 Kuala Lumpur

Malaysia

Phone Number (office): +603-7949 2061

Email: suhailimohd@ummc.edu.my

\begin{abstract}
Freeze drying is a dehydration method to dry bone under freezing environment, enabling removal of water with no or minimial effects on bone strength and durability. Larger size bones obviously require longer freeze drying time to reduce water content to the required level for long term storage at room temperature. For small size bone cubes or chips, it is a normal practice to pool cortical and cancellous bones for freeze drying. The study was aimed at determining if different type of bones of the same size influence the drying time. Human bone cubes of $10 \mathrm{~mm} \times 10 \mathrm{~mm} \times 10 \mathrm{~mm}$ were prepared from cortical bone of tibiae and cancellous bone from femoral heads. The bone cubes were freeze dried to reduce water content to less than $6 \%$. Moisture content was monitored using gravimetric method.Weight and density of cortical bone were significantly higher than cancellous bone despite of having similar small size $(p<0.05)$. Cortical bones (density $2.05 \pm 0.35 \mathrm{~g} / \mathrm{cm}^{3}$ ) with initial water content of $10.93 \%$ required 5 hours to freeze dry, while cancellous bone cubes (density $0.72 \pm 0.44$ $\mathrm{g} / \mathrm{cm}^{3}$ ) with initial water content of $78.95 \%$ required only 1.87 hours. This study confirmed that the structure hence density of human bone cubes determine the freeze drying time. Therefore in the standard operating procedure for freeze drying of bone allograft cubes, high density cortical bone cubes and low density cancellous bone cubes must be freeze dried separately despite being of similar small size.
\end{abstract}

Keywords: Cortical, Cancellous, Freeze Drying, Water Content

\section{Introduction}

Bone allograft has been used in orthopaedic and maxillofacial surgery for various purposes (1). Load bearing reconstruction requires fresh frozen large bone that is mechanically strong and can provide good structural support (2). On the other hand, freeze dried bone graft in small size is useful for trauma surgery, spinal fusion and to fill bone gap in tumor resections (3). Bone allograft has been an alternative to autograft despite having the risk of contamination and disease transmission which are becoming the main safety concerns (4). However, freeze dried bone allografts can be supplied in large quantity with long shelf life and are readily available for use $(1,5)$.

Freeze drying or lyophilisation is a dehydration method which is commonly used to reduce water content for long term storage (6). Freeze dried bone can be stored at room temperature and conveniently handled during despatch or transportation. In freeze drying process, bones are frozen and followed by reducing the surrounding pressure to allow the frozen water in the material to sublimate directly from solid phase to gas phase. In primary drying of the freeze drying, the unbound or free water is removed while in the secondary drying the bound water is removed. The final residual water content is lowered to the desired level by varying the drying time. Freeze drying causes no or minimal damage to the bone properties compared to the other dehydration methods that use high temperatures.

Human bone has two main structures, compact and spongy. Compact structure of cortical bone is generally of higher density hence has lower water content than spongy structure of cancellous bone owing to the increased mineralisation $(7,8)$. Cortical bone is stronger, harder and 
stiffer whilst cancellous bone is weaker, softer and easy to break. Cortical bone provides $80 \%$ of the bone mass in the human body (9) while the cancellous makes up $20 \%$ of all bones. Cortical bone has low porosity ranging between $5 \%$ to $10 \%(10)$ as compared to cancellous bone which is of high porosity ranging between $50 \%$ to $90 \%$ (11). The density and porosity of bone certainly imply a variation in water content since an increase in porosity has been shown to be allied to an increase in the water-lipid content of bone (8). Cortical bone contains between $10 \%$ to $20 \%$ water and the rest mainly consist of collagen fibres and inorganic mineral in the form of small crystals (12) and also other substances such as proteins and inorganic salts. Free bone water is located in pore spaces with dimensions in micrometers while bound water is bounded to collagen and the matrix substrate. Tightly bound water is imbedded in the crystals of the apatite-like mineral component (13). The density of bone is related to mineral content, the organic composition and also water. Therefore, water plays an important role in influencing the physical properties of bone tissues (14).

Freeze drying process time depends on the amount of water to be removed and the size of bone. In routine bone processing practices, large size bone is freeze dried separately from small size bone because the large bone requires longer time to dry. However there is no clear requirement to dry separately small size bones of different structures. Small bones of the same size are normally pooled for freeze drying to save time and electrical cost. The present study was aimed to identify influence of bone structure on the freeze drying process of the small size human cortical and cancellous bone cubes to the desired percentage of water content of less than $6 \%$. The findings would validate the standard operating procedure for freeze drying cycle for bone allograft cubes for preservation purpose.

\section{Materials and Methods}

\section{Bone Procurement and Sample Preparation}

The study was approved by the University Malaya Medical Centre (UMMC) Ethics Committee (Ethic No: 1037.8). Femoral heads were procured from 3 healthy living donors during orthopaedic surgeries while tibiae were procured from 3 deceased donors, with mean age of 29.6 years old. Donor consents were obtained prior to bone procurement and the donors were screened according to the exclusion criteria of the UMMC Bone Bank, as described in the previous work (15). Medical and social history of the donors were strictly reviewed. Bone swabs taken immediately after procurement were sent for bacteriological test. Donors' blood samples were sent for serological tests for HIV, Hepatitis B, Hepatitis $C$ and Syphilis. The procured bones were kept in $-80^{\circ} \mathrm{C}$ freezer while waiting for the test results. Only bones with negative results were used in this study.

The shaft of tibia bones and femoral heads were cut into small cubes of approximately $10 \mathrm{~mm} \times 10 \mathrm{~mm} \times 10 \mathrm{~mm}$ $\pm 0.5 \mathrm{~mm}$ which were measured by calibrated digital calipher (Mitutoyo CD-6 ASX, Japan). The specimens were weighed to determine wet weight or initial weight before freeze drying. Volume was obtained using Archimedes concept of water displacement. The bone cubes were processed according to the protocol described by Nather and Tay (2010) (16) and each bone cube was given graft identification. The bone cubes were subjected to processing and freeze drying, as illustrated in the summarised work flow in Figure 1.

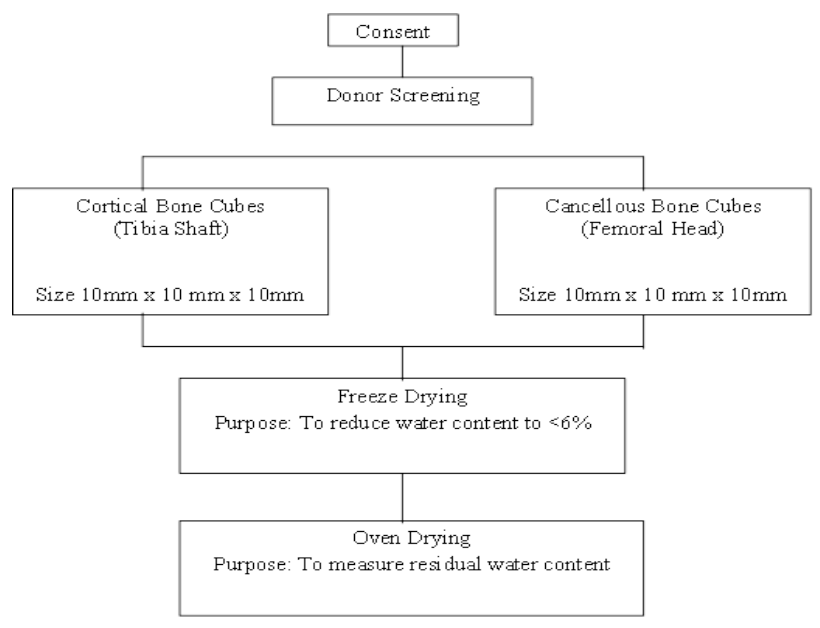

Figure 1: Work Flow Summary of the processing and freeze drying of Cortical and Cancellous Bone Cubes

\section{Freeze Drying of Bone}

Bone cubes were washed with normal saline after the dissection of soft tissues. The cortical and cancellous bones were treated in $70 \%$ ethanol to remove lipid and to inactivate some microbes for 3 hours and 1 hour respectively. The treated cortical and cancellous bones were soaked in warm sterile distilled water and pasteurized in water bath at $60^{\circ} \mathrm{C}$ respectively for 3 hours and 1 hour to inactivate viruses. After the final dissection of soft tissues under aseptic condition, the bone cubes were treated with $0.5 \%$ sodium hypochlorite for human immunodeficiency viruses (HIV) inactivation and washed in sterile water for 3 times. All bones were kept in the freezer $-75^{\circ} \mathrm{C} \pm$ $10^{\circ} \mathrm{C}$ overnight prior to freeze drying as described by Hilmy et al. (2007) (17). Freeze drying was carried out using lyophiliser (FreeZone, LABCONCO, U.S) whereby the chamber was precooled at $-46 \pm 4^{\circ} \mathrm{C}$. The samples were arranged on the stainless steel plate and placed on the rack inside the chamber. The bones were freeze dried at $-46 \pm 4^{\circ} \mathrm{C}$ and under pressure of $0.042 \mathrm{mmHg}$. Samples of cortical bone (tibia) were taken out at interval times of 0,4 , 8,24 and 28 hours while cancellous (femoral head) bones were taken at $0,1,2,3,4,5$ and 6 hours, in triplicate. The bones were subjected to residual water content analysis using gravimetric method (oven drying). The residual water contents were plotted against the freeze drying times to get the water content profiles until almost constant.

For validating the process, bone cubes were freeze dried for various drying durations: 0 to 28 hours for cortical bone 
cubes and 0 to 360 minutes for cancellous bone cubes. Weights of freeze dried bone cubes were monitored while drying at $100^{\circ} \mathrm{C}$ and water content was calculated when the dry weight was constant. The monitored bone weights for varying freeze drying durations were compared.

\section{Determining Residual Water Content by Oven Drying Method}

Water content by oven drying method was carried out as described by Yusof and Hilmy (2007) (18). Oven drying by gravimetric method is the common dehydration laboratory method to totally dry the bones, normally to determine the water or moisture content of processed bones (19). The bone samples were heated in oven (MEMMET Gmbh, Germany) at $100^{\circ} \mathrm{C}$, the temperature which was used earlier by Fernandez-Seara et al. (2004) (20), to remove all water or until the weight was constant. Samples were weighed before and after drying using electric balance (Ohaus cv313, U.S). The water content based on dry weight was calculated as follows:

$$
\begin{gathered}
\text { Water Content }(\%)=\frac{\mathrm{W} 1-\mathrm{W} 2}{\mathrm{~W} 2} \times 100 \% \\
\text { Where, } \\
\mathrm{W} 1=\text { Weight before oven drying }(\mathrm{g}) \\
\mathrm{W} 2=\text { Weight after oven drying }(\mathrm{g})
\end{gathered}
$$

\section{Data Analysis}

Level of significance of the means for variables (weight, density and initial water content) of human cortical and cancellous bone cubes were tested using one-way analysis of variance (ANOVA). The data were tabulated and analyzed using IBM's SPSS Statistical Software for Windows (IBM SPSS, version 22, Chicago, IL, USA). Any p-values of less than 0.05 were considered to be statistically significant.

\section{Results}

Despite having the same size of $10 \mathrm{~mm} \times 10 \mathrm{~mm} \times 10 \mathrm{~mm}$ $\pm 0.5 \mathrm{~mm}$, cortical and cancellous bone cubes seemed to have different structure and pore size which were reflected in the initial weights (Figure 2).

\begin{tabular}{|l|l|l|}
\hline & Cubes & Close-up Structure \\
\hline $\begin{array}{l}\text { Cortical } \\
\text { Bone }\end{array}$
\end{tabular}

Figure 2: Cortical and cancellous bone cubes with close-up structure having different porosity.
The cortical bone from tibia $(\mathrm{n}=15)$ had mean weight of $0.187 \pm 0.035 \mathrm{~g}$ and mean density of $2.047 \pm 0.348 \mathrm{~g} / \mathrm{cm}^{3}$; whilst the cancellous bone from femoral head $(n=18)$ had lower mean weight of $0.114 \pm 0.068 \mathrm{~g}$ and lower mean density of $0.718 \pm 0.437 \mathrm{~g} / \mathrm{cm}^{3}$ (Table 1). The mean weight and density of the cortical bone were significantly higher than the cancellous bone despite having similar small size cube $(p<0.05)$.

Table 1: Weight, density and initial water content of human cortical bone cubes from tibia and cancellous bone cubes from femoral head (mean* \pm standard deviation (SD)).

\begin{tabular}{|l|l|l|l|}
\hline Bone cube & $\begin{array}{l}\text { Weight } \pm \text { SD } \\
(\mathrm{g})\end{array}$ & $\begin{array}{l}\text { Density } \pm \text { SD } \\
\text { (g/cm3) }\end{array}$ & $\begin{array}{l}\text { Initial } \\
\text { Water } \\
\text { Content } \pm \text { SD } \\
\text { (\%) }\end{array}$ \\
\hline $\begin{array}{l}\text { Cortical bone } \\
(\mathrm{n}=15)\end{array}$ & $\begin{array}{l}0.187 \pm \\
0.035 \mathrm{a}\end{array}$ & $\begin{array}{l}2.047 \pm \\
0.348 \mathrm{c}\end{array}$ & $\begin{array}{l}10.929 \pm \\
0.583 \mathrm{e}\end{array}$ \\
\hline $\begin{array}{l}\text { Cancellous } \\
\text { bone } \\
(\mathrm{n}=18)\end{array}$ & $\begin{array}{l}0.114 \pm \\
0.068 \mathrm{~b}\end{array}$ & $\begin{array}{l}0.718 \pm \\
0.437 \mathrm{~d}\end{array}$ & $\begin{array}{l}78.950 \pm \\
6.186 f\end{array}$ \\
\hline
\end{tabular}

$* n=$ number of bones. The means followed by different alphabets in each column are significant at $p<0.05$ level

Residual water content of bone samples decreased with increasing freeze drying time. For cortical bone with $10.93 \%$ initial water content, the water content was reduced by $55.4 \%$ after 8 hours drying time and was reduced further by $80.2 \%$ after more than 24 hours of drying (Figure 3 ). Based on the water content profile in Figure 3 , the freeze drying process for cortical bones was completed after 6 hours when the water content of the processed bone reached less than $6 \%$ as recommended by the American Association of Tissue Banks (AATB) Standards (using gravimetric method).

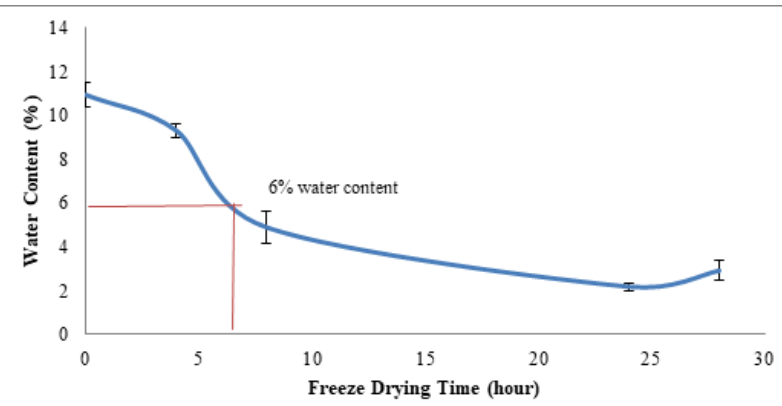

Figure 3: Water content profile of cortical bone cubes during freeze drying process

For cancellous bone, with $78.95 \%$ initial water content which is almost 8 times higher than the water content in the cortical bone, required only 2 hours drying time to reduce the water by $94.3 \%$ of the initial weight (Figure 4 ). The freeze drying process for cancellous bone completed after 1.87 hours (112 minutes) when the water content 
was reduced to $6 \%$ as obtained from the water content profile in Figure 4.

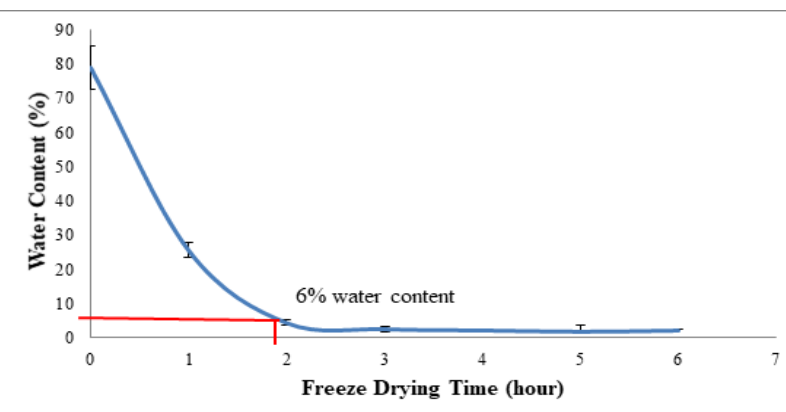

Figure 4: Water content profile of cancellous bone cubes during freeze drying process.

To validate further the process, bone cubes were freeze dried for different durations. Weights of freeze dried bone cubes after different durations of freeze drying and the control (not freeze dried) were constant after 5 hours oven drying, as shown in Figure 5 and Figure 6 for the cortical and cancellous bones, respectively. The water content was calculated based on the constant weight.

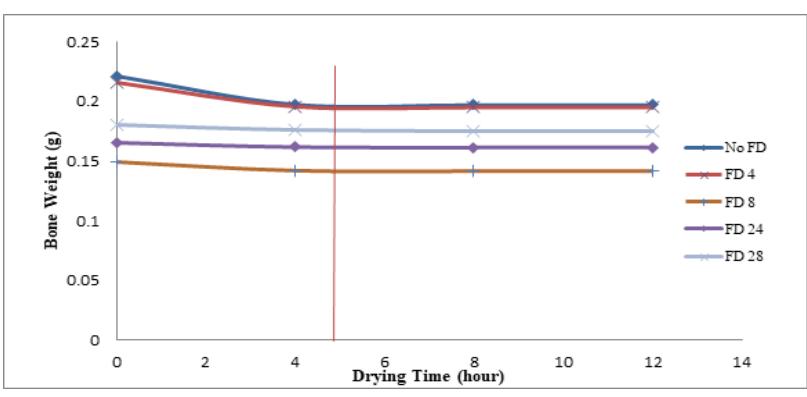

Figure 5: Weight of freeze dried cortical bone cubes during oven drying at $100^{\circ} \mathrm{C}$ : No FD - not freeze dried (control), FD 4 - freeze dried for 4 hours, FD 8 - freeze dried for 8 hours, FD 24 - freeze dried for 24 hours and FD 28 - freeze dried for 28 hours.

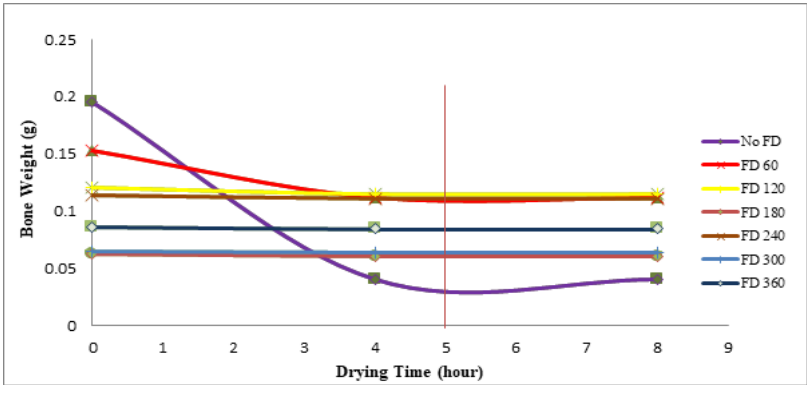

Figure 6: Weight of freeze dried cancellous bone cubes during oven drying at $100^{\circ} \mathrm{C}$ : No FD - not freeze dried (control), FD 60 - freeze dried for 60 minutes, FD 120 freeze dried for 120 minutes, FD 180 - freeze dried for 180 minutes, FD 240 - freeze dried for 240 minutes, FD 300 - freeze dried for 300 minutes and FD 360 - freeze dried for 360 minutes.

\section{Discussion}

Water or moisture content is the quantity of water contained in a material. Water content in bone may vary with bone structure and density. Mohiuddin (2013) managed to relate the density of different types of cortical bone to varying water content whereby the water is comparatively high in scapula (density $=1.615 \mathrm{~g} / \mathrm{cm}^{3}$, water content $12 \%$ ) when compared to the rib (density $=1.622 \mathrm{~g} /$ $\mathrm{cm}^{3}$, water content $11 \%$ ) and low in femur (density $=2.097$ $\mathrm{g} / \mathrm{cm}^{3}$, water content $10 \%$ ) (14). This report is in agreeable with our results on cortical bone with a density of 2.047 $\pm 0.348 \mathrm{~g} / \mathrm{cm}^{3}$ and water content of $10.93 \%$. The finding is also in line with the in vivo cortical bone (bone in the living body) which contains only $10 \%$ to $20 \%$ water of its dry mass with approximately $60 \%$ to $70 \%$ bone minerals as reported by Herring (1977) and low porosity of $5 \%$ to $10 \%$ as reported by Cowin $(1990)(10,12)$. The cancellous bone with a lower density of $0.718 \pm 0.437 \mathrm{~g} / \mathrm{cm}^{3}$ seemed to hold more water (78.95\%) and according to Goldein et al. (1990), it is highly porous with $50 \%$ to $90 \%$ porosity (11).

Freeze drying is the preferred method for drying thermally sensitive tissues. The low temperature minimizes unwanted reactions that usually occur in other dehydration processes and frozen samples are dried under vacuum by sublimation of the ice present (21). The parameter for drying time needs to be validated as freeze drying process of tissues seemed to be influenced by the type of bones (structure, density, size). Free water which is located in the pore spaces between the bone structure can easily be removed via primary drying of the freeze drying process. Unlike freeze drying, oven drying removes two parts of water fraction which are the free water and the collagenbound water $(22,23)$.

The compact structure of the cortical bone holds less free water within the pores as the surface area is smaller than the pores of the spongy structure of the cancellous bone, as described earlier by other workers $(10,11)$. Total surface area of the cancellous bone is larger than the cortical bone, in the ratio of approximately 2:1 (24). According to Itturia et al. (2010), in spite of the lower initial water content in cortical bone, most of the water present is bound water while in cancellous bone it is free water based on heat transfer study (21). Therefore the bone structure (porosity) and type of water, clearly influence the freeze drying time to dehydrate bones. Our study revealed that during the initial stage of freeze drying, the drying rate for the cortical bone was $1.15 \%$ per hour which was much lower than the drying rate in the cancellous bone which was $53.35 \%$ per hour.

According to American Association of Tissue Banks (AATB) Standards, the water content of bone should be reduced to less than $6 \%$ for the purpose of long term preservation (6). However in practise, Nather and Tay (2010) suggested that the desired water content of processed bones is within $5 \%$ to $8 \%$ by freeze drying using lyophiliser to avoid over dehydration (16). At average density of $2.047 \pm 0.348 \mathrm{~g} /$ $\mathrm{cm}^{3}$, the cortical bone in this study required 5 to 7.5 hours 
whilst the cancellous bone required only 1.75 to 2.0 hours of freeze drying time to reduce the water content within 5 to $8 \%$, respectively. This study determined that the drying time for cancellous bone is three times shorter than that of the cortical bone indicating that type of bones clearly influence the freeze drying time. The practice of pooling small size bones from the same donor regardless of the different structures due to the limited number of lyophiliser available in a bank should be reviewed. It is not advisable to pool the bones for drying. Removing cancellous bones at the early stage of the freeze drying cycle and then continue drying the cortical bones is not encouraged as this practice would disturb the drying cycle of the later resulting in insufficient drying.

In case the cancellous bone is freeze dried together with the cortical bone for 5 hours, the residual water content of the cancellous bone would be very low at $1.9 \%$, which is over dehydrated thus may take longer time to rehydrate as claimed by Nather and Tay (2010).; Besides, there is a risk of losing both bone strength and toughness according to Nyman et al. $(16,25)$. Therefore freeze drying of cancellous bone for a long period will unncessarily affect its properties and it is also uneconomical. It is recommended that bones of different types having distinctive different structure and weight cannot be dried in the same freeze drying batch. The cancellous bone of high pore size and low density will have different sublimation time for the removal of free and bound water compared to the more compact cortical bone. The findings of this study can be applied to improve the standard procedures for freeze drying process of bone allograft cubes of different bone types.

\section{Conclusion}

The dense cortical bone cubes with a low water content of $10.93 \%$ needs freeze drying time longer than the more porous cancellous bone cubes with a high water content of $78.95 \%$ to reduce the water content to the desired residual level of less than $6 \%$ for the purpose of long term preservation. The bone structure certainly implies a variation in residual water content and influences the drying time of freeze drying process. Therefore bone cubes of similar size but of different structures and density must be freeze dried separately to ensure proper drying and to avoid over dehydration.

\section{Acknowledgement}

This study was funded by University Malaya Research Grant (RG542-13HTM). The authors would like to thank UMMC Bone Bank personnels who were involved directly and indirectly in completing the study.

\section{Competing Interests}

All authors declared that they have no competing interests.

\section{References}

1. Grover V, Kapoor A, Malhotra R, Sachdeva S. Bone Allografts: A review of safety and efficacy. Indian J Dent Res. 2011; 22(3): 532-37.

2. Nather A, Han YY. Biology of healing of bone allograft. In: Allograft Procurement, Processing and Transplantation, edited by Nather A, Yusof N, Hilmy N, 175-194. Singapore: World Scientific Publishing; 2010.

3. Mankin HJ, Doppelt S, Tomford W. Clinical experience with allograft implantation. Clin Orthop Relat Res. 1983; 174: 69-86.

4. Tomford WW. Transmission of disease through transplantation of musculoskeletal allografts. Bone Joint Surg Am. 1995; 77:1742-54.

5. Cornu O, Banse X, Docquier PL, Luyckx S, Delloye C. Effect of freeze drying and gamma irradiation on the mechanical properties of human cancellous bone. J Orthop Res. 2000; 18: 426-31.

6. American Association of Tissue Banks (AATB). Standards for Tissue Banking. American Association of Tissue Banks. 12 ${ }^{\text {th }}$ ed. Virginia: McLean; 2008.

7. Buckwalter JA, Cooper RR. Bone structure and function. In: Instructional Course Lectures, edited by Surgeons TA, 27-48. Illinois: The American Academy of Orthopaedic Surgeons; 1987.

8. Timmins PA, Wall JC. Bone Water. Calcif Tissue Int. 1977; 23: 1-5.

9. Recker RR. Embryology, anatomy and microstructure of bone. In: Disorders of Bone and Mineral Metabolism, edited by Coe FL, Favus MJ, 219-240. New York: Raven Press; 1992.

10. Cowin SC. Properties of cortical bone and theory of bone remodelling. In: Biomechanics of Diarthrodial Joints, edited by Mow VC, Ratcliff A, Woo SL, 119-153. New York: Springer; 1990.

11. Goldstein SA, Hollister SJ, Kuhn JL, Kikuchi N. The mechanical and remodelling properties of trabecular bone. In: Biomechanics of Diarthrodial Joints, edited by Mow VC, Ratcliff A, Woo SL, 61-81. New York: Springer; 1990.

12. Herring GM. Methods for the study of glycoproteins and proteoglycans of bone using bacterial collagenase: Determination of bone sialoprotein and chondroitin sulfate. Calcif Tissue Int. 1977; 24: 29-36.

13. Kokabi N, Bae W, Diaz E, Chung BC, Bydder MG, Du J. Ultrashort TE MR imaging of bovine cortical bone: The effect of water loss on the $T_{1}$ and $T_{2}$ relaxation times Magn Reson Med. 2011; 66: 476-82.

14. Mohiuddin S. Changes in bone density as a function of water content. World J Med Sci. 2013; 8 (1): 48-51.

15. Mohd S, Samsuddin SM, Ramalingam S, Ng WM, Yusof N, Zaman TK, Mansor A. Assessing bone banking activities at University of Malaya Medical Centre. Cell Tissue Bank. 2015; 16 (4): 523-30.

16. Nather A, Tay LM. Processing of bone and musculoskeletal soft tissue allografts. In: Allograft Procurement, Processing and Transplantation, edited 
by Nather A, Yusof N, Hilmy N, 335-360. Singapore: World Scientific Publishing; 2010.

17. Hilmy N, Abbas B, Anas F. Validation for procesing and irradiation of freeze-dried bone grafts. In: Radiation in Tissue Banking: Basic science and clinical applications of irradiated tissue allografts, edited by Nather A, Yusof N, Hilmy N, 219-234. Singapore: World Scientific Publishing; 2007.

18. Yusof N, Hilmy N. Physical and mechanical properties of radiaiton-sterilized amnion. In: Radiation in Tissue Banking: Basic science and clinical applications of irradiated tissue allografts, edited by Nather A, Yusof N, Hilmy N, 155-168. Singapore: World Scientific Publishing; 2007.

19. Smith JW. Observations on the water content of bone. J Bone Joint Surg Br. 1964; 46B:553-62.

20. Fernandez-Seara MA, Wehrli SL, Takahashi M, Wehrli FW. Water content measured by proton-deuteron exchange NMR predicts bone mineral density and mechanical properties. J Bone Miner Res. 2004; 19(2): 289-96.

21. Itturia M, Rodriguez Emmenegger C, Viegas $R$, Zeballos J, Wodowoz O, Alvarez I, Bologna Alles A. Basic design of lyophilization protocols for human bone tissues. Lat Am Appl Res. 2010; 40:147-51.

22. Neuman WF, Neuman MW. The chemical dynamics of bone mineral. Chicago: University of Chicago Press; 1958.

23. Edsall JT. The size, shape and hydration of protein molecules. In: The Proteins, edited by Neurath $\mathrm{H}$, Bailey K, 549-726. New York: Academic Press; 1953.

24. Kimmel DB, Jee WS. Measurements of area, perimeter, and distance: details of data collection in bone histomorphometry. In: Bone histomorphometry: Techniques and Interpretation, edited by Recker, R., 50-62. Boca Raton: CRC Press; 1983.

25. Nyman JS, Roy A, Shen X, Acuna RL, Tyler, JH, Wang, $X$. The influence of water removal on the strength and toughness of cortical bone. J Biomech. 2006; 39: 931-38. 